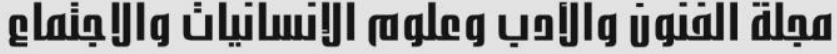

Journal of Arts, Literature, Humanities and Social Sciences www.jalhss.com

\section{دراسة حول تطور الكتابة العربية من النقوش على الكي الالواح الى الكتابة على الورق من النق}

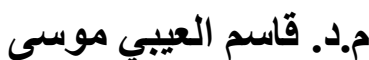 \\ كلية الهندسة ـ الجامعة المستنصرية ـ العراق العيل \\ الايميل: kasim_la@yahoo.com
}

الملخص الإب الكتانة العزبة في جاهن عرف العرب الكتابة العربية في جاهليتهم ، و إن الكتابة العربية التي تستخدم الان ترجع إلى عصر سابق للإسلام

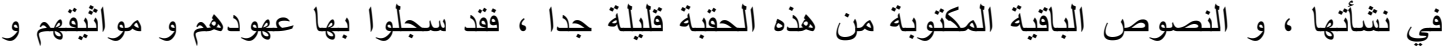

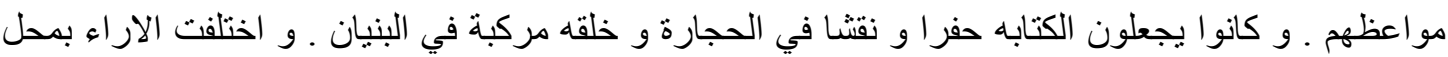
نشوء الخط العربي فمنهم من يقول ان نشوءه في طور سيناء و منهم من قال في الثام عند الغساسنة ، ومنهم من ون ون قال ان الخط العربي قريب من الكتابة النبطية المتأخرة . و عند ظهور الإسلام اعطى الكتابة اتجاها علميا جديدا لم يكن معروفا من قبل ، فقد خدمت الكتابة الإسلام خدمة لا يضار عها شيئا آخر و كانت بالنسبة له خير ا من السيف في كثير من الاحيان ، و المخطوط هو الكتاب المكتوب هن بخط اليد وهو ما كتب بالمداد على الورق ، سواء أكان الورق مصنو عا من طر اطيس البردي أو من الرقوق أو أو الون

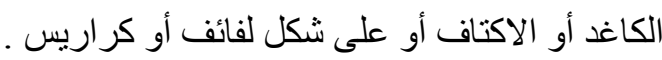
وقد عرف العرب أدوات الكتابة في جاهليتهم و هي نفسها التي استعملت في العهد النبوي الثريف و صحابته في

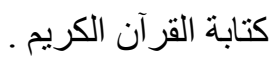
حيث تم تدوين القرآن على الرقاع ، و الاضلاع ، و و العسب ، و اللفاف ـ و و بعد الانتهاء من تدوينه و تطور ظاهرة التدوين بعد منتصف القرن الأول الهجري بدأت كتابة السير و المغازي ، ولثي كما حظى الحديث النبوي الثريف بخصوصية في التدوين . أما التأليف فهو يعتبر المصدر الأول للمخطوطات العربية ، فقد شهد او اخر القرن الأول زيادة في التآليف و كثرة في

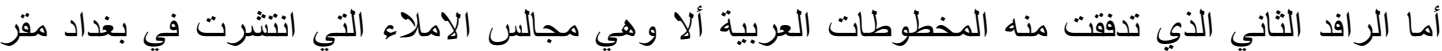

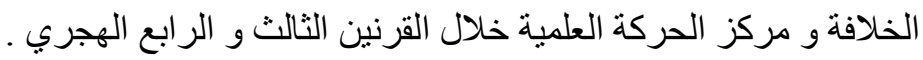
الكلمات المفتاحية: الكتابة، المخطوط، التأليف، النقوش، التدوين. 


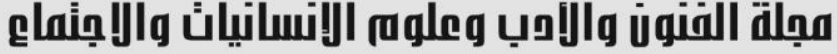

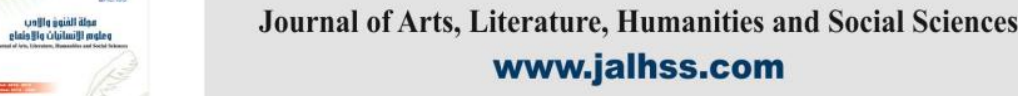

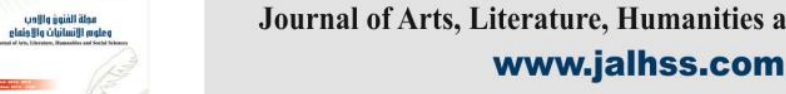

Volume (58) September 2020

العدد (58) سبتمبر 2020

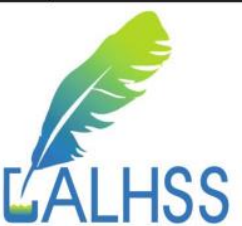

\section{A Study on The Development of Arabic Writing From Inscriptions on The Tables to The Papers}

\author{
Dr. Kasim Al-Aeabi Moosa \\ College of Engineering - Al- Mustasirryah University - Iraq \\ Email: kasim_la@yahoo.com
}

\begin{abstract}
The Arabs knew Arabic writing in their ignorance, and the Arabic writing that is now used dates back to an earlier era of Islam in its inception, and the remaining texts written from this era are very few, they have recorded their covenants, covenants and sermons. And they used to make the writing a dig and inscription in the stones and created a compound in the building. Opinions differed in the place where the Arabic calligraphy originated, some of whom say that it originated in the Sinai phase, some of whom said in Damascus at the time of the Ghassana, and some of them said that Arabic calligraphy is close to the late Nabataean writing.

When Islam appeared, writing gave a new scientific direction that was not known before, and writing served Islam as a service that was not matched by anything else, and for him it was better than the sword in many cases, and the manuscript is the handwritten book, which is written in the hand book, whether the paper is made of papyrus, parchment, cagadic, shoulders, scrolls or booklets.

The Arabs knew the tools of writing in their ignorance, the same ones that were used in the Prophet's reign and his companions in writing the Holy Qur'an.

The Qur'an was written on the ribs, ribs, ass, and loaves. After the completion of its codification and the development of the phenomenon of blogging after the middle of the first century began writing biographies and battles, and the Prophet's hadith enjoyed the specificity of blogging.

As for the composition, it is considered the first source of Arabic manuscripts, it witnessed the end of the first century an increase in translations and a large number of books amounted to a camel load for Ebn- Abbas (dead $68 \mathrm{AH}$ )

The second tributary from which the Arabic manuscripts flowed is the dictation councils, which spread in Baghdad, the seat of the caliphate and the center of the scientific movement during the $3 \mathrm{rd}$ and 4 th centuries.
\end{abstract}

Keywords: Writing, Manuscript, Authoring, Inscriptions, Blogging. 


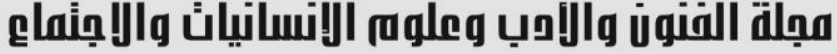

Journal of Arts, Literature, Humanities and Social Sciences www.jalhss.com

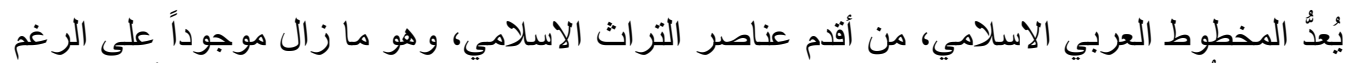

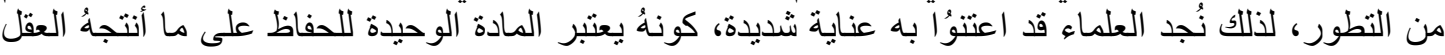

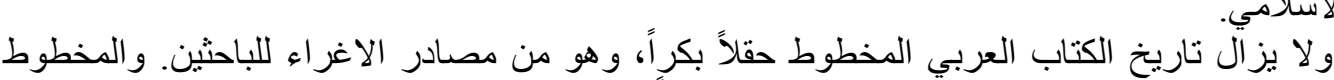

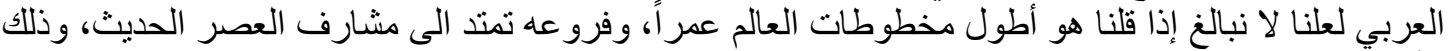

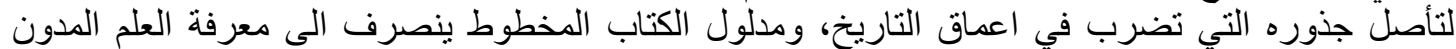

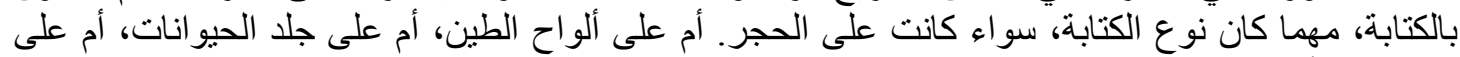

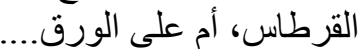

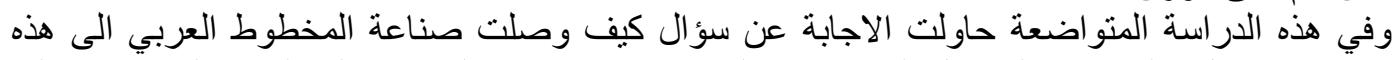

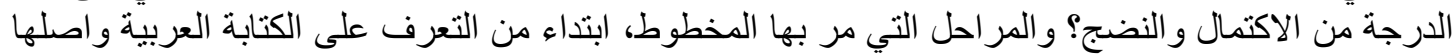

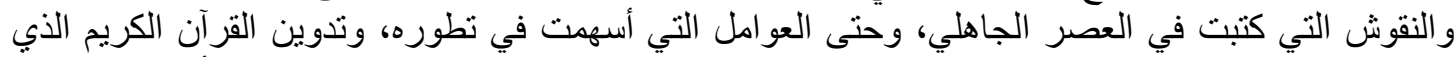

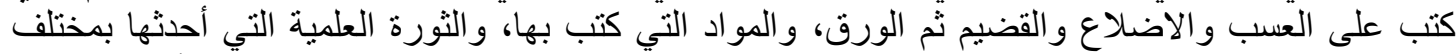

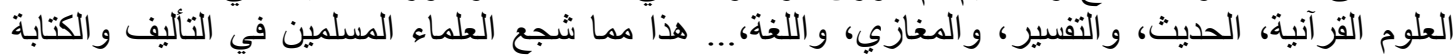
وخاصة في القرنين الثالث و الر ابع الهجري.

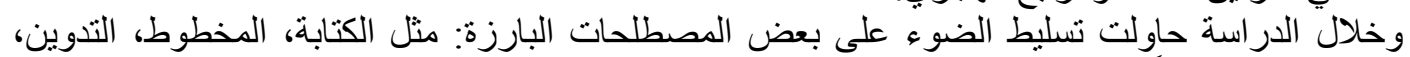

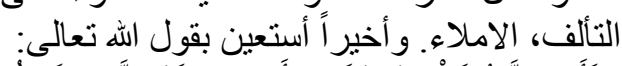

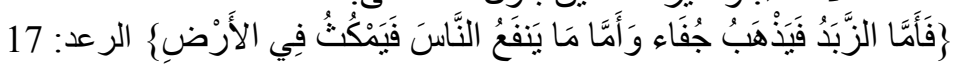

\section{المبحث الاول \\ نشأة الكتابة العربية}

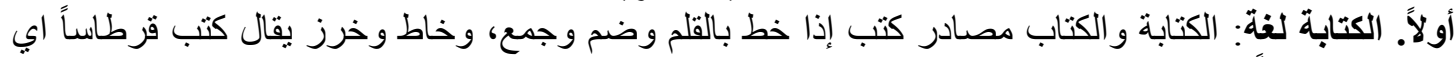

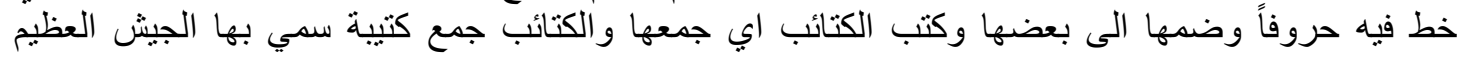
ل الاجتماعه.

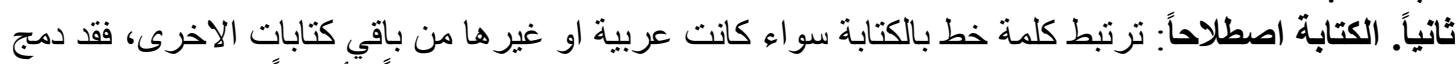

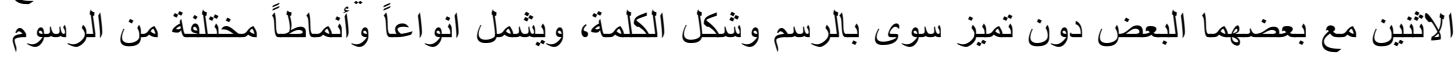

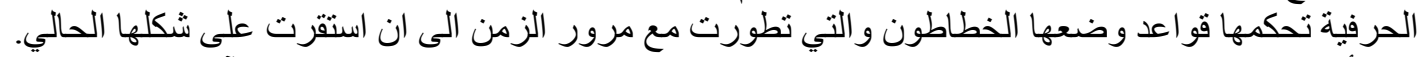

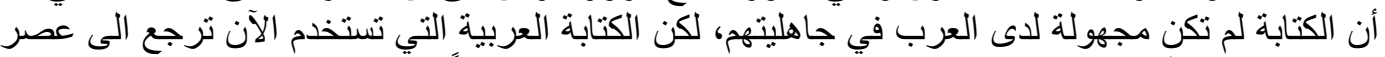

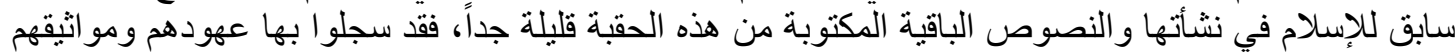

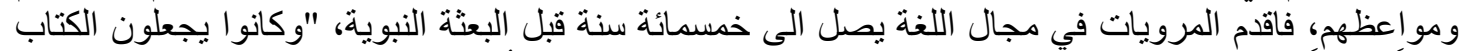

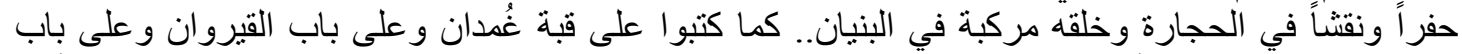

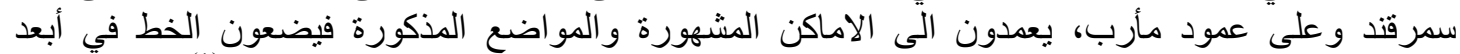

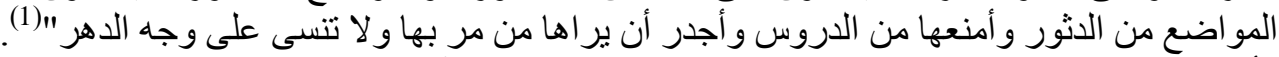

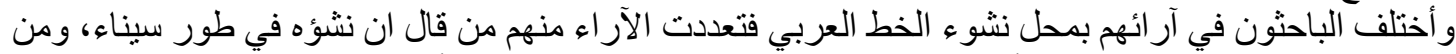

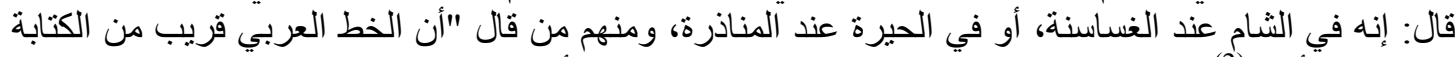

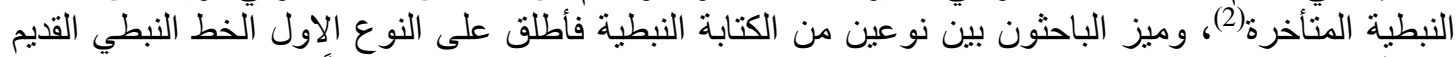

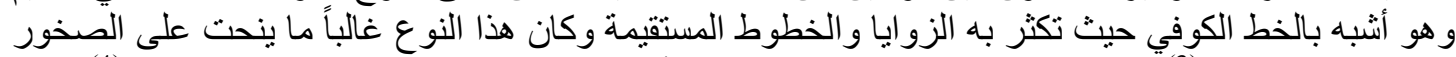

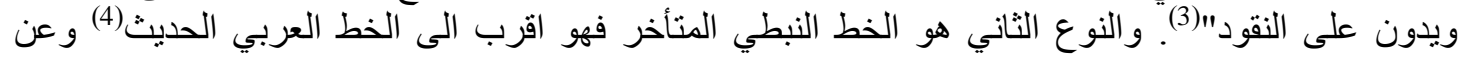

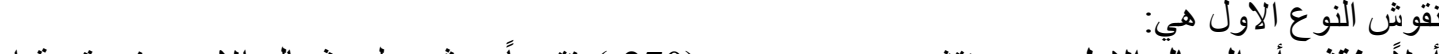

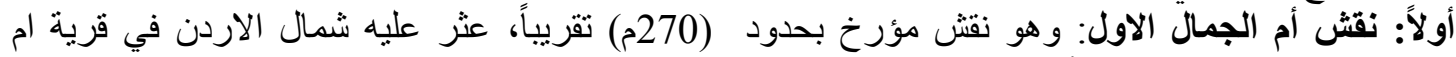

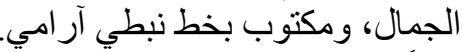

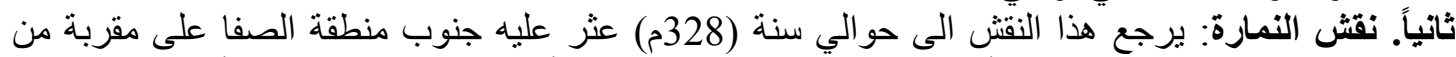

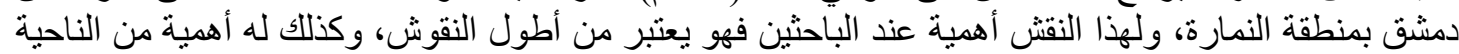




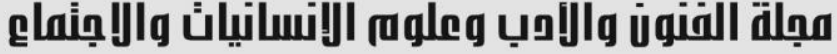
Journal of Arts, Literature, Humanities and Social Sciences www.jalhss.com

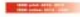

اللغوية و الكتابية، حيث نجد كلمات عربية مثل (جاء و هزم ووكل و الثعوب) كما نجد فيه تر اكيب وجمل عربية

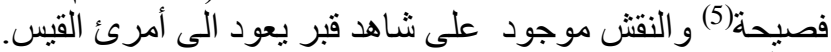

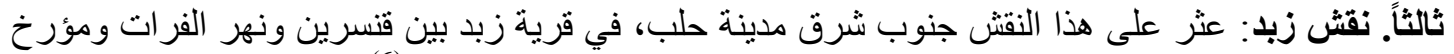

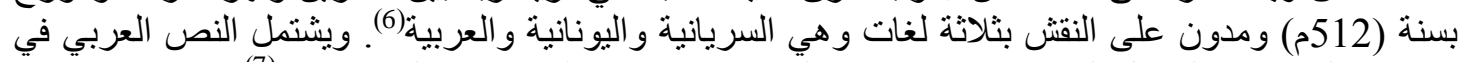

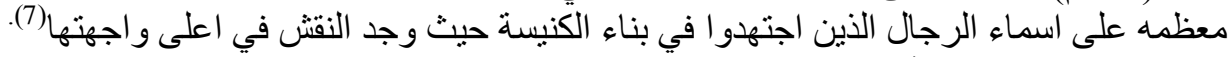

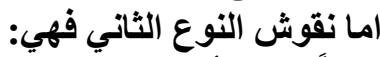

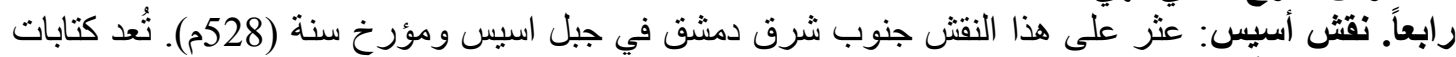

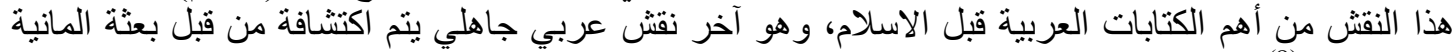

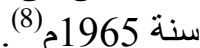

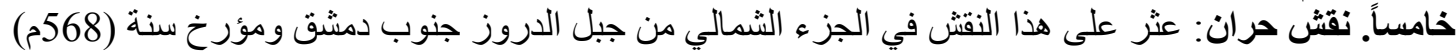

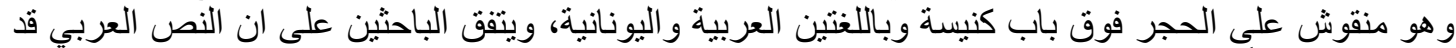

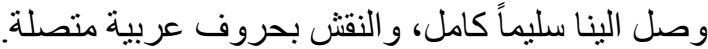

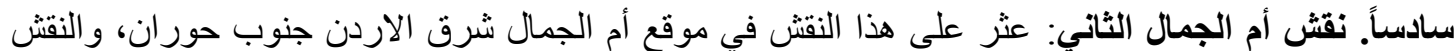

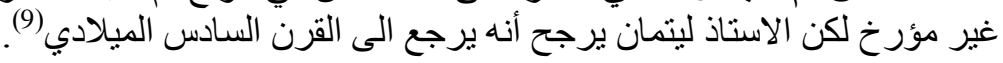

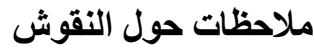
1. ان انظات اغلب النقوش المكتشفة في الثشام وشبه جزيرة سيناء وشمال الحجاز واقليم حوران، تتحصر الفترة

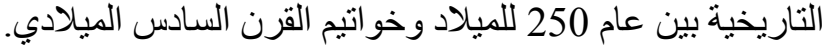
2. نقار ام الجمال الاول يوضح ان أصل الصل الكتابة النبطية القديمة هو الخط الآرمى، حيث عده الاستاذ ليتمان نقتشاً آر امياً. 3.

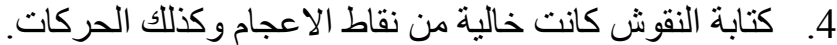
5. ظلت بعض النوف الحروف النبطية تحتفظ بها الكتابة العربية، وبالمقابل بعض الحروف النبطية لم تعد تستعمل في

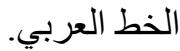

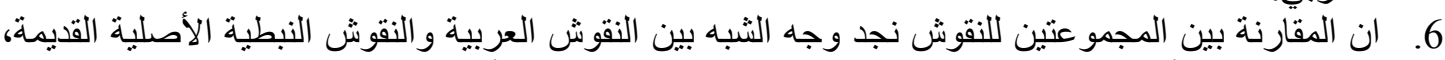
ونرى التطور الذي أدرك الكتابة بشكل عام والخط النبطي الذي تجاوز أصله الى الصورة النئ العربية التي حذقها

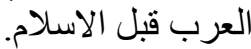
ومما يؤكد تطور الكتابة ما قاله الاستاذ ابر اهيم جمعه حيث مرت بثلاثة مر احل هي (10):

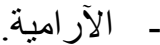
- مرحلة انتقال من الخط الار امي المربع الى الخط النبطي.

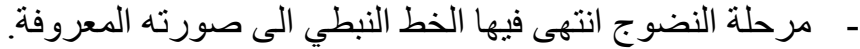
وتتشير المصادر على ان الخط الذي انتهى الى العرب من ديار النبط عرفتُ بأسماء عربية عدة فيذكر منها: (الخط

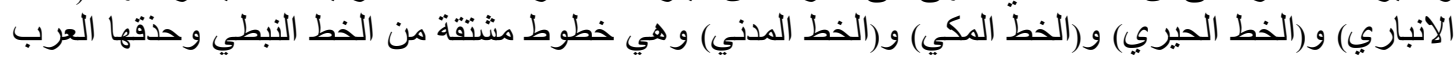

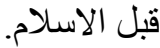

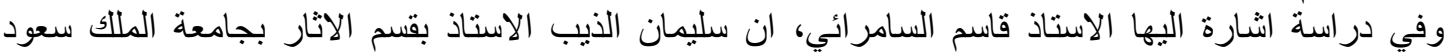

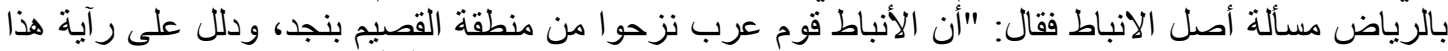

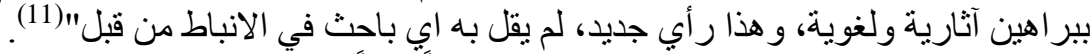

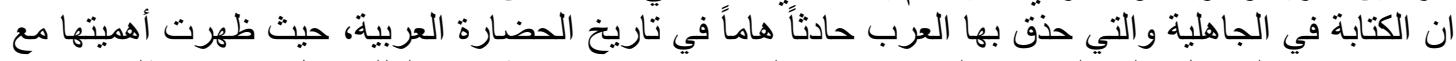

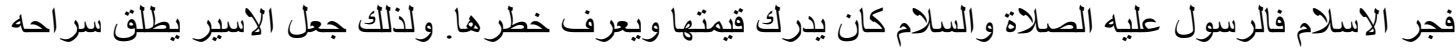

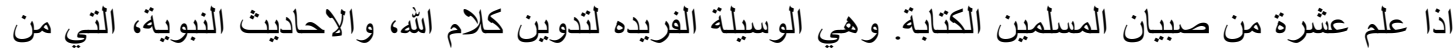

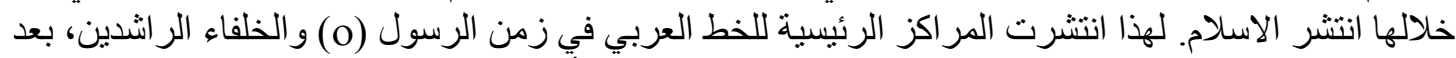

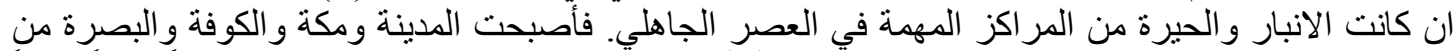

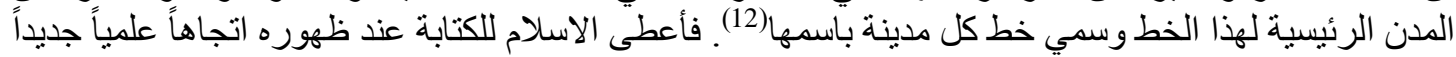




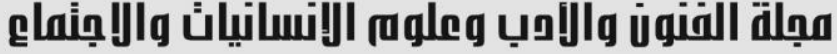

\author{
Journal of Arts, Literature, Humanities and Social Sciences
} www.jalhss.com

Volume (58) September 2020

العدد (58) سبتمبر 2020

لم يكن معروفاً من قبل فقد خدمت الكتابة الاسلام خدمة لا يضار عها شيء آخر وكانت بالنسبة له خير اً من السيف

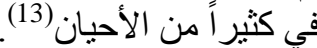

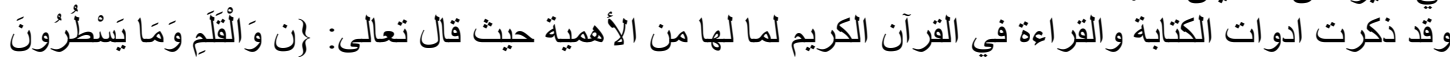

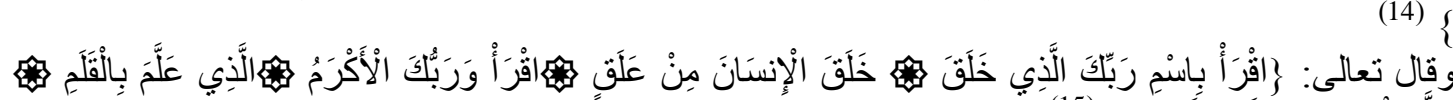

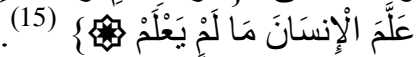

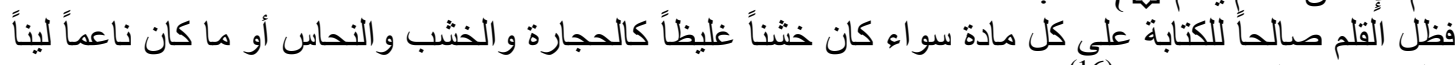
كالقرطاس و الورق والاديم (16).

\section{المبحث الثاني \\ تطور صناعة المخطوط}

أولاً: تعريف المخطوط لغة: "مأخوذ من خط بالقلم وغيره، يخطُ خَّطا، كَتَب أي صوّر اللفظ بحروفٍ هجائية" (17).

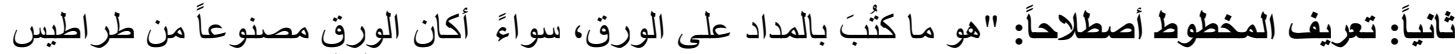

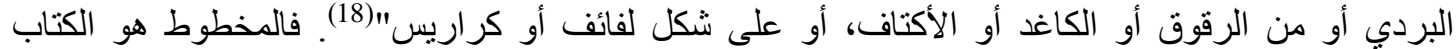

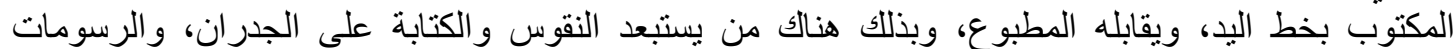

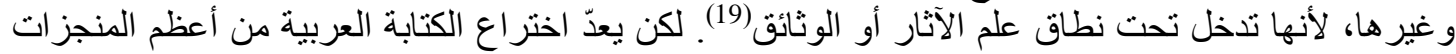

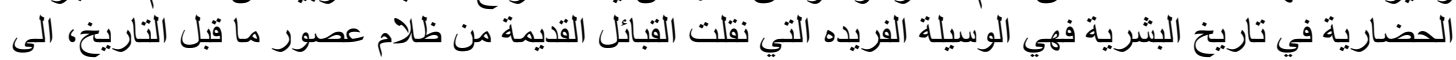

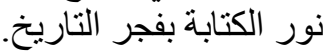

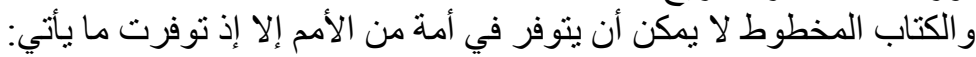

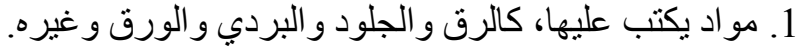

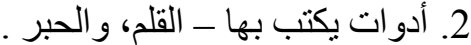

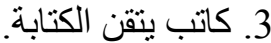

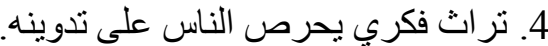
اما المواد التي كانت يكتب عليها في عصر فئ البداوة فهي من صميم البيئة الصحر اوية التي يعيش فيها السكان

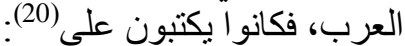

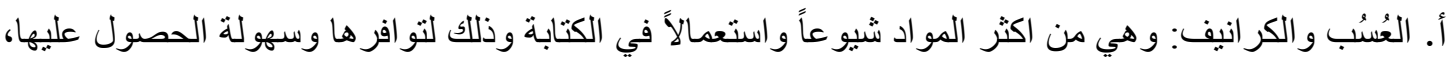

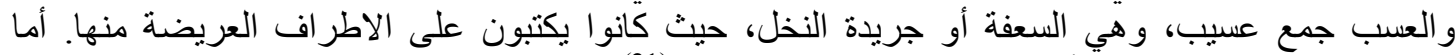

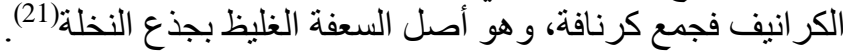

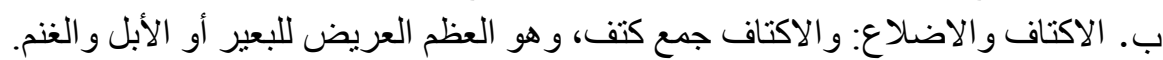
ج. اللخاف: وهي الحجارة البيض الرقاق. د. الأديم و القضيم: وهي أنواع من الجلود، فالاديم هو الجلد الأحمر أو الددبوغ. و القضيم هو الجلد الابيض الذي يكتب عليه. هـ. المهارق: هو لفظ فارسي معرب، يقول عنه ابن منظور : "ثوب حرير أبيض يسقي الصمخ ويصقل ثم يكتب

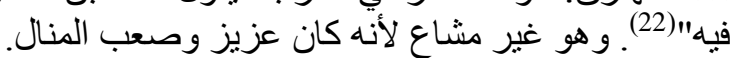

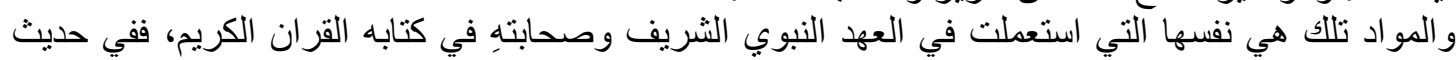

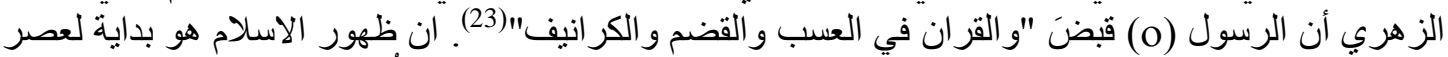

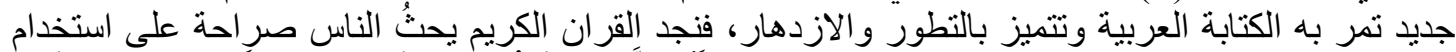

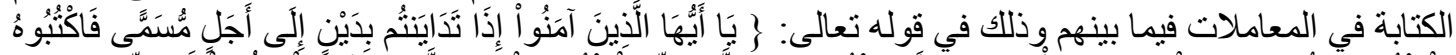

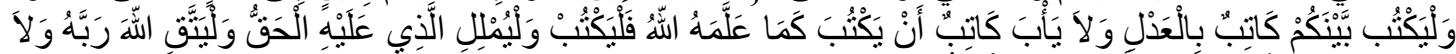

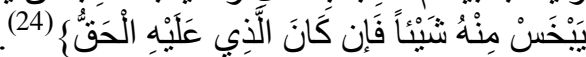
وقد عرف العرب ادوات اخرى للكتابة في جاهليتهم كالبردي باسم "القرطاس" ويعني ورق البردي والرق

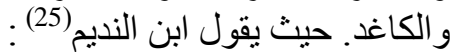




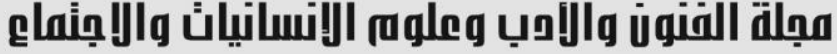

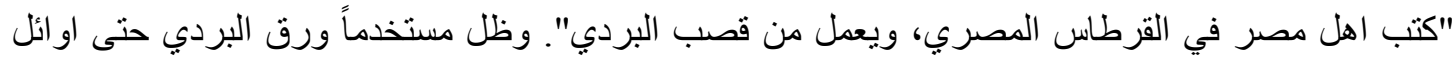

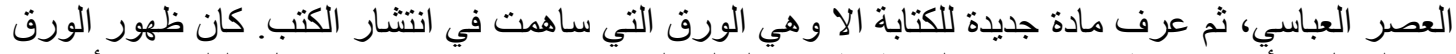

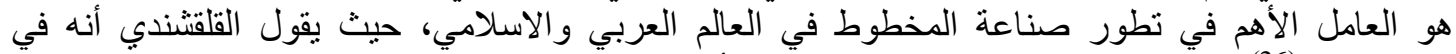

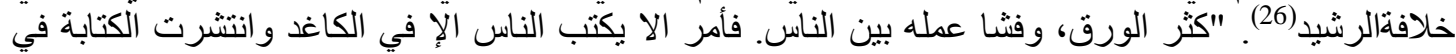

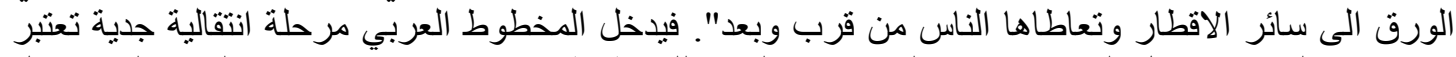

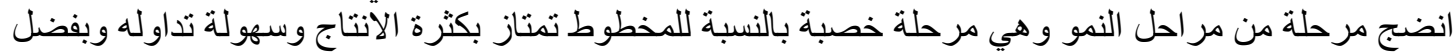

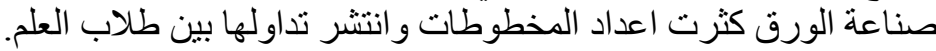

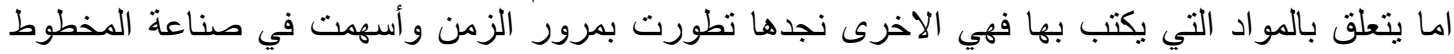

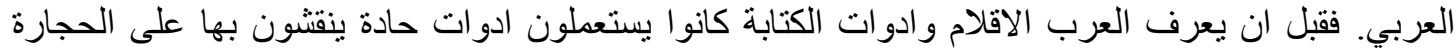

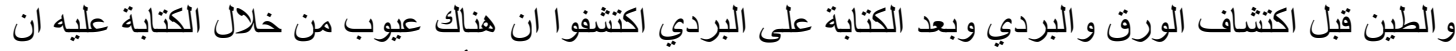

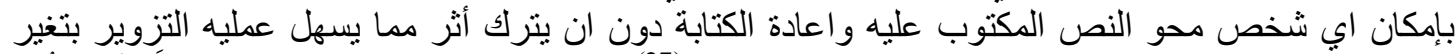

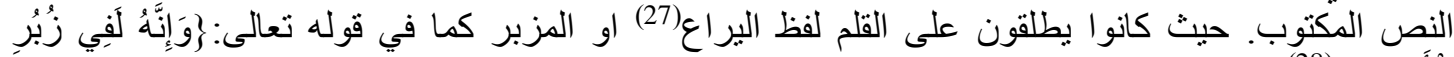

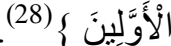

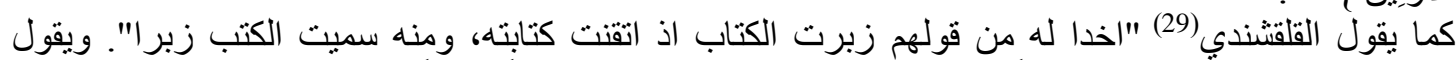

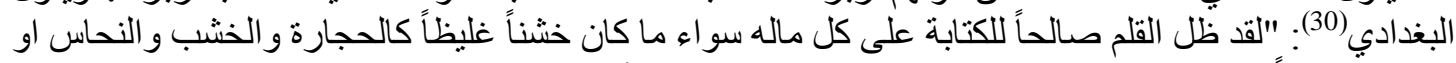
ما كان ناعماً لينا كالقرطاس والورق، والاديم". ويذكر القرآن الكريم القلم في مواضع عديدة ومنها قوله تنعالى: (31)

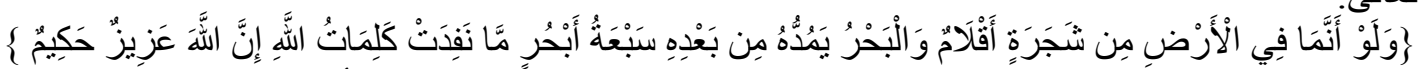

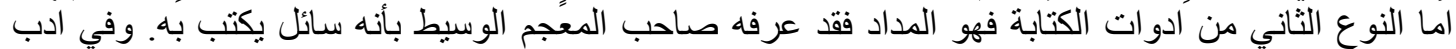

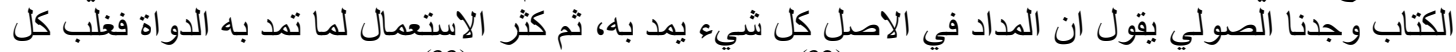

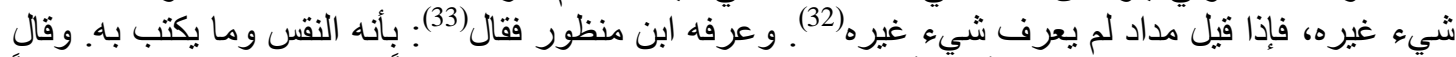

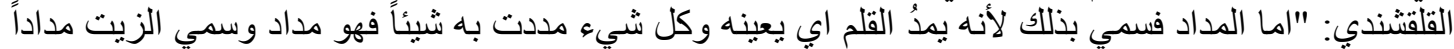
لان السر اج يمد به الليقة مما يكتب به فيه فهو مداد" لاديه

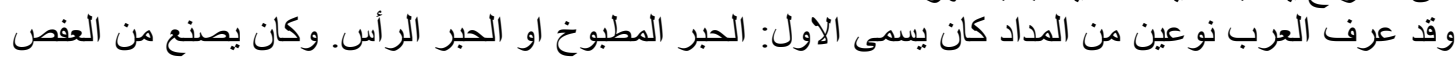

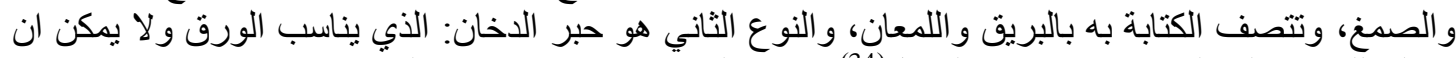

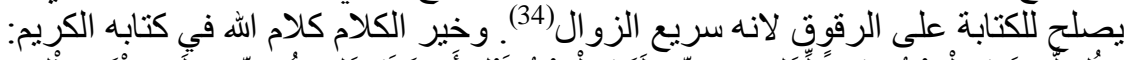

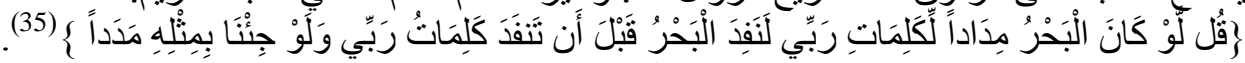

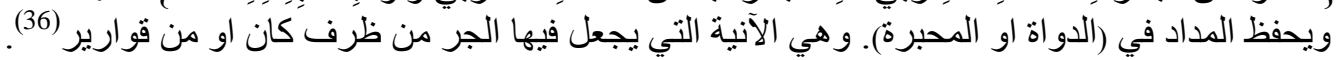

\section{المبحث الثالث \\ التدوين والتأليف}

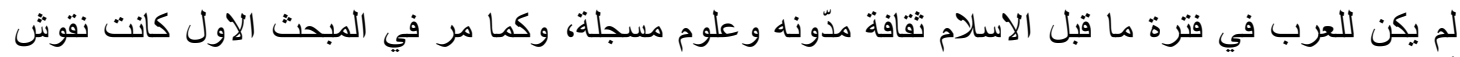

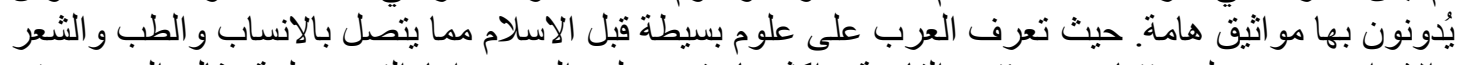

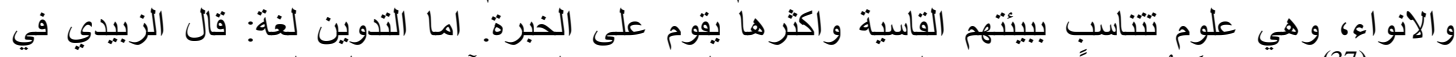

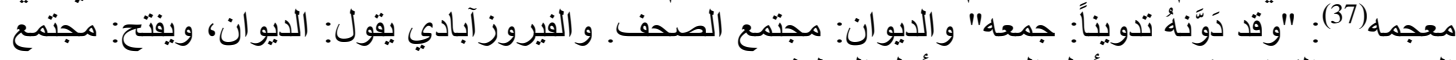

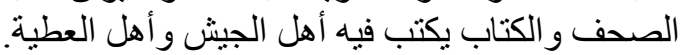

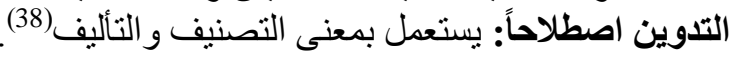

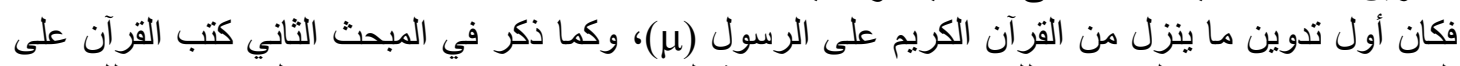

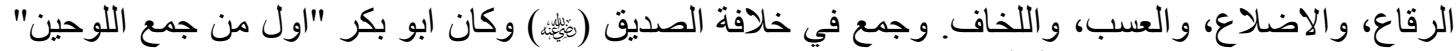

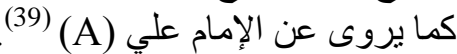

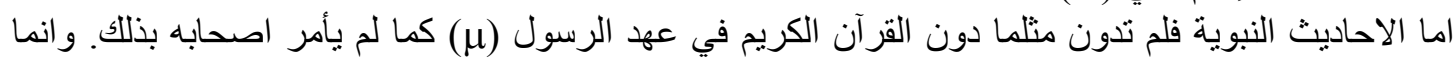

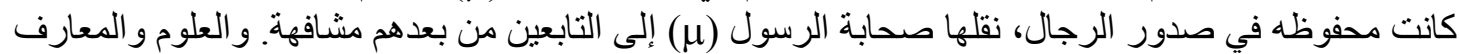

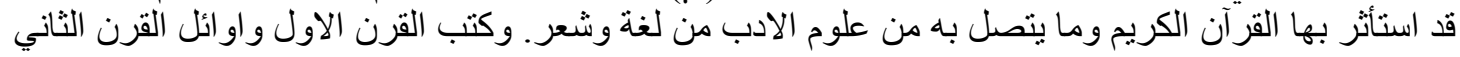




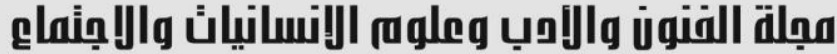

Journal of Arts, Literature, Humanities and Social Sciences www.jalhss.com

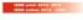

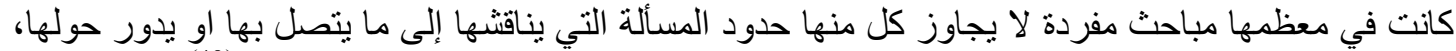

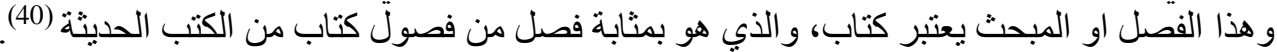

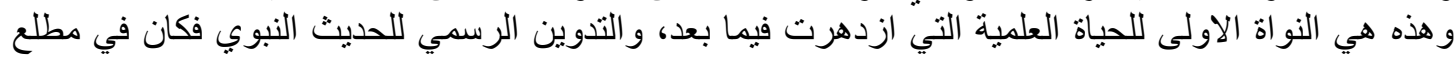

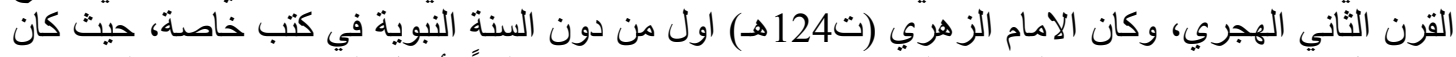

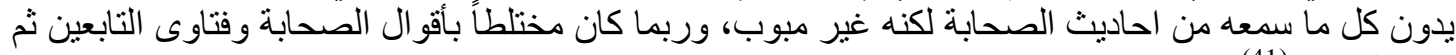
شـاع التدوين (41) ملان.

\section{الحاجة للتدوين بعد الاسلام}

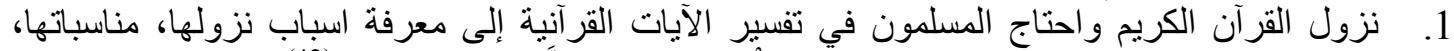

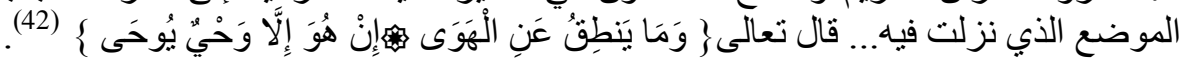

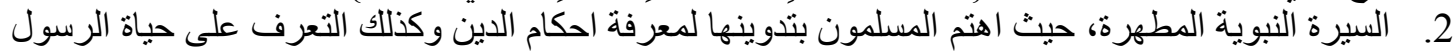

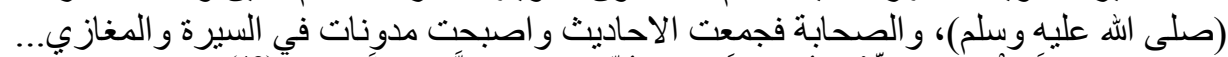
قالَ تعالى:

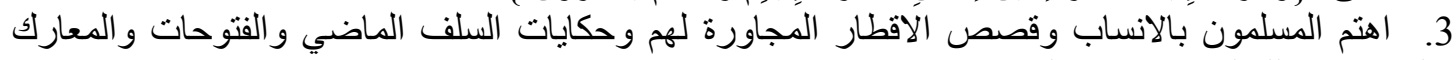

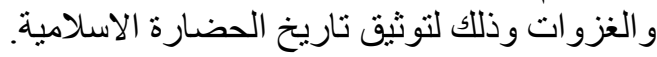

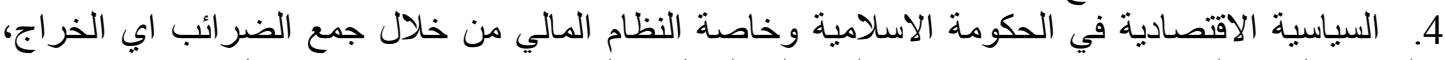

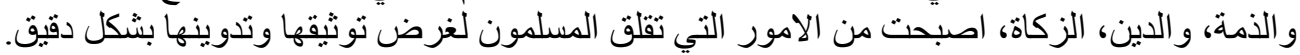

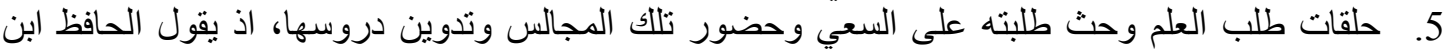

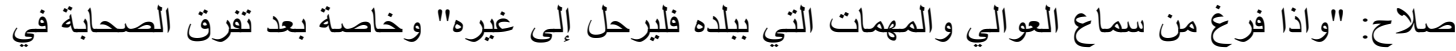

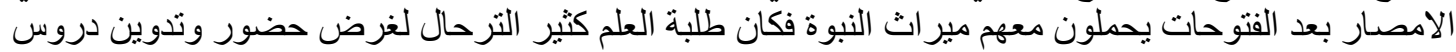

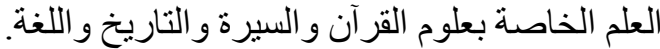

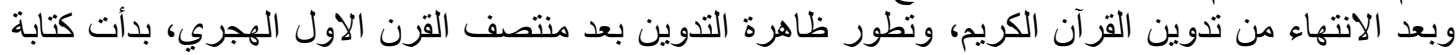

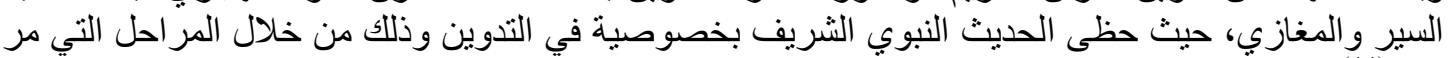

أ. كتابة الحديث: دونت الاحاديث في عصر الصحابة وأوائل التابعين في كراريس صغيرة سميت بالصحيفة او

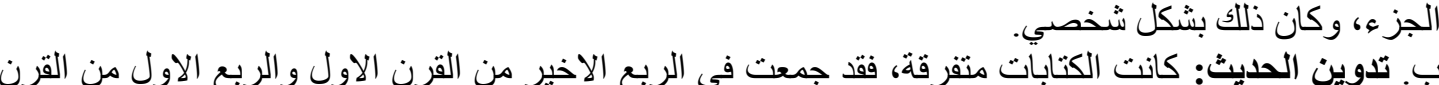

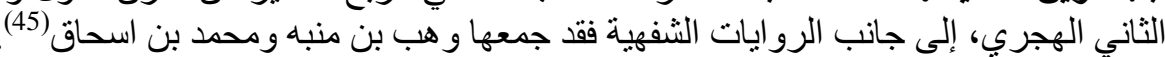
ج. تصنيف الحديث: بداية التنظيم المنهجي للاحاديث المدونة، شهنتها هذه المرحلة، سو اء حسب الابن البواب الفقهية،

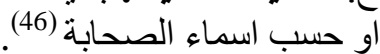

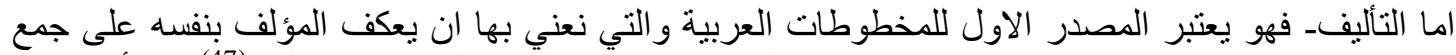

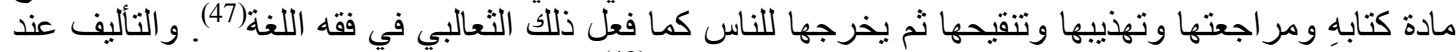

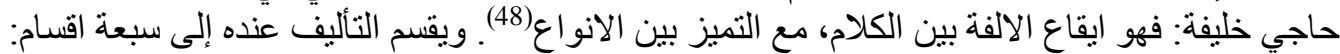

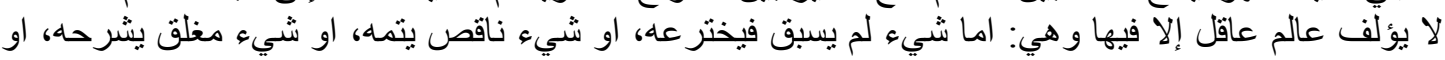

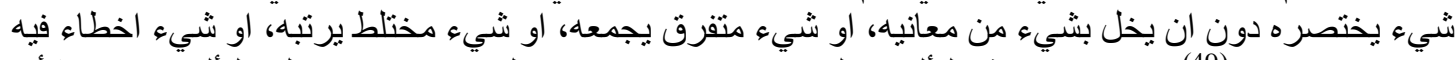

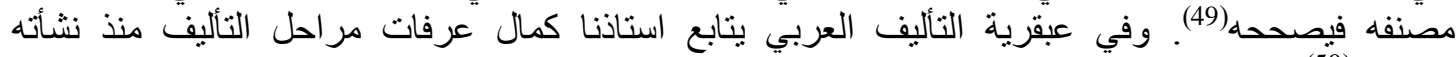
فلخصها (50). 1. الرواية والحفظ و السماع في المرحلة الثفهية في بداية الاسلام "حفاظ القرآن فور نزوله - المحنثون

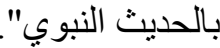
2. التدوين: تدوين القرآن الكريم - تدوين السير و الفقه و الحديث و غير ها.

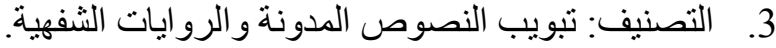

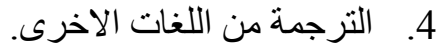
5. التأليف المكتوب: الابداع و المسؤولية الفردية في الثعر و المقالات و التأليف العلمي و التاريخي... 


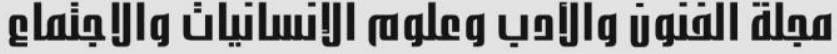

\author{
Journal of Arts, Literature, Humanities and Social Sciences
} www.jalhss.com

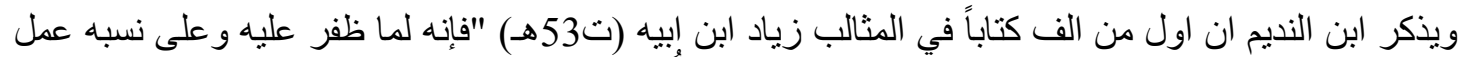

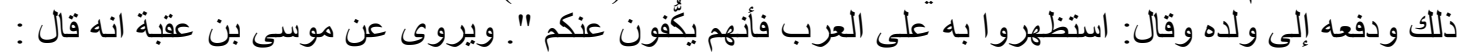

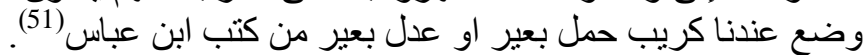

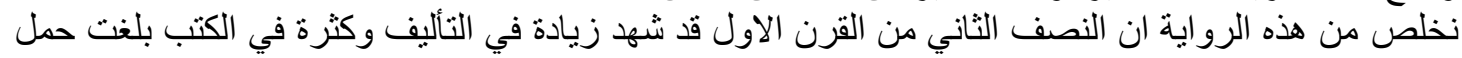

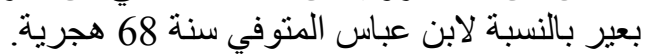

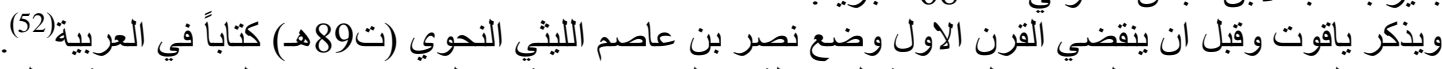

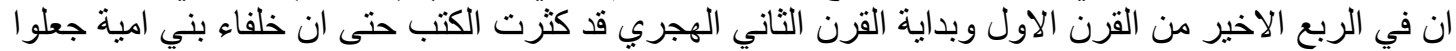

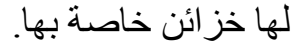

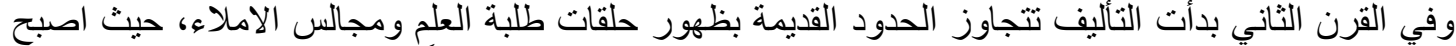

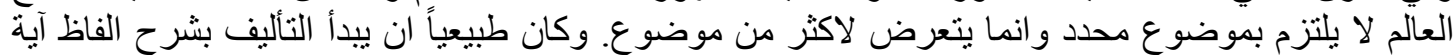

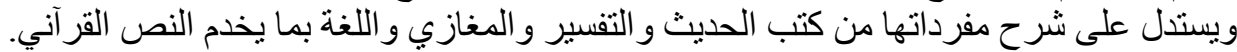

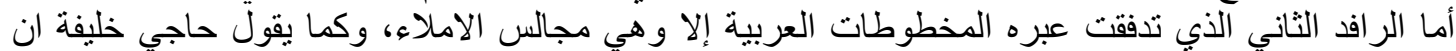

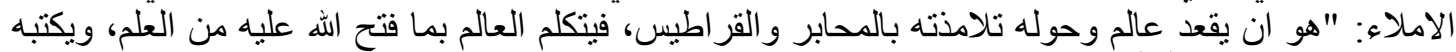

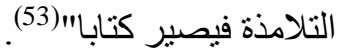

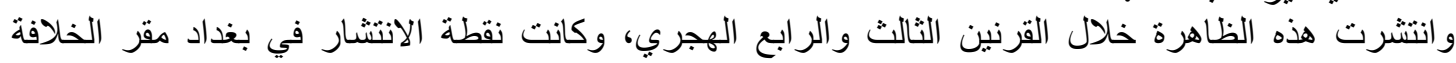

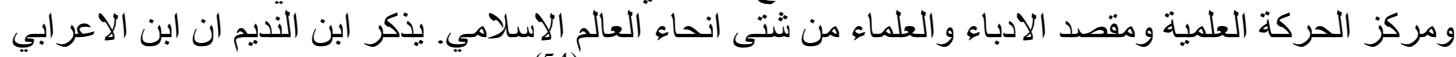

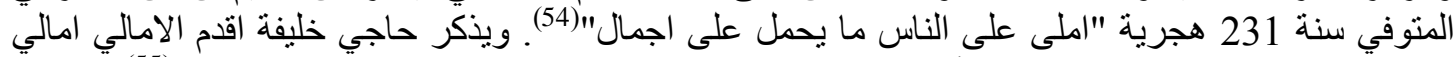

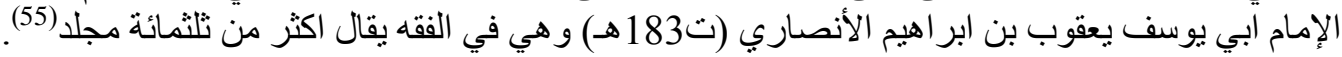

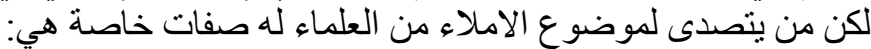
أ. أن يكون العالم له ثقة بنفسه.

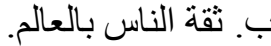

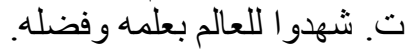
وذللك لان حلقات الدرس لم تكن جاهزة ولا مكتوبة، و إنما تعتمد على الارتجال و الثقافة العلمية و الدينية للعالم .

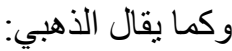
"كان سائر الائمة يتكلمون على حفظه او يروون العلم من صحف صحيحة غير مرتبه".

الخاتمة

1. يعتبر القرآن الكريم أول مخطوط عربي تطلق عليه كلمة "مخطوط" ولم تكن قبله الكتابات العربية سوى

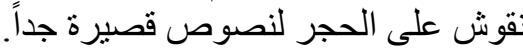
2. تطور الكتابة والخط النبطي بشكل خاص الذي تجال تجاوز أهله إلى الصورة العربية التي حذقها العرب قبل

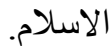
3. ظهور الاسلام يعتبر عاملاً مهماً في ناريخ المخطوط العربي، وهو الذي وسع دائرة المعرفة عند العرب،

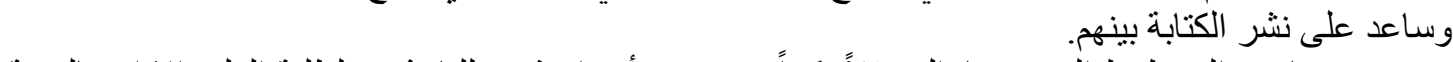
4. يعتبر تاريخ المخطوط العربي ماز ال حقلاً بكراً، ومصدر أغراء شديد للباحثين ولطلبة العلم، إلا انه بالنسبة

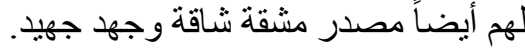

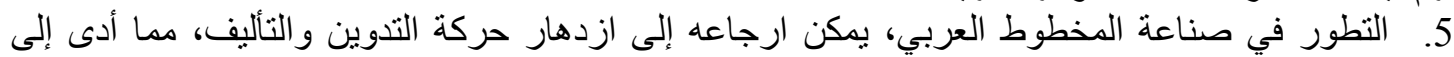
تنامي الانتاج الفكري للعلماء المسلمين.

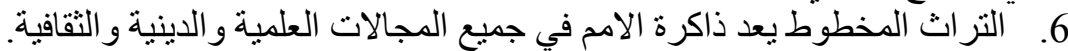

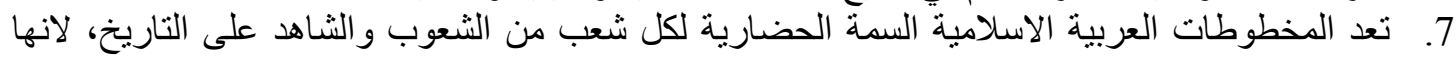

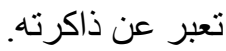




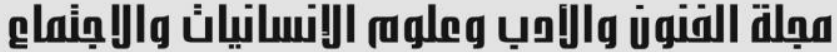

Journal of Arts, Literature, Humanities and Social Sciences www.jalhss.com

$$
\begin{aligned}
& \text { (41) السنة ومكانتها في التشريع، ص } 104 \text { (4) } 104 \\
& \text { (42) سورة النجم: آية } 3 \text { و4 التينة } \\
& \text { (43) سورة النحل: آية } 44 \text { (42) سورة }
\end{aligned}
$$

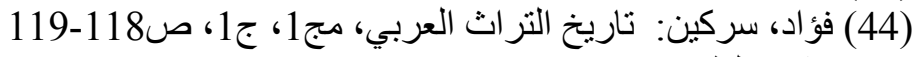

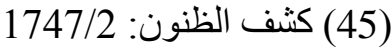

$$
\begin{aligned}
& \text { (46) فؤاد سركين: المصدر السابق، ص ص } 199
\end{aligned}
$$

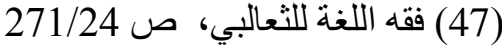

$$
\begin{aligned}
& \text { 35/1 (48) كثف الظنونة } \\
& \text { (49) الثكعة، مصطفى: مناهج التأليف عند العلماء العرب، ص618 } \\
& \text { (50) كمال نبهان: عبقرية التأليف العربي، صاليف }
\end{aligned}
$$

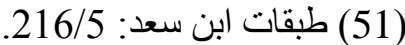

$$
\begin{aligned}
& \text { (52) (52) معجم الادباء: 224/19 (52) }
\end{aligned}
$$

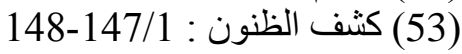

$$
\begin{aligned}
& 103 \text { : } 103 \text { (54) ابن النديم: الفهرن : } \\
& \text { 164/1 : 155) كثف الظنون الفن : }
\end{aligned}
$$

\section{المصادر}

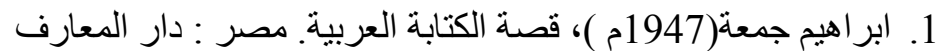

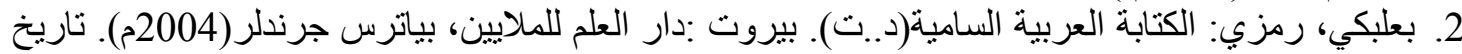

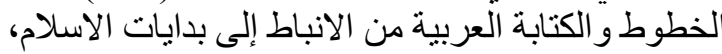

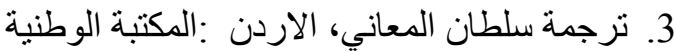
4. الثُعالبي، ابو منصور عبد الملك (1954 م): فقه اللغة وسر العربية( ط2) تحقيق مصطفى السقا وآخرين، 5. الجاحظ، ابو عثمان عمرو(1938م) الحيوان ،تحقيق عبد السلام هارون، القاهرة: مكتبة المصطفى البابي 6. جو اد علي(1957م. ) ناريخ العرب قبل الاسلام. بغداد: مطبعة المجمع العلمي العر اقي،

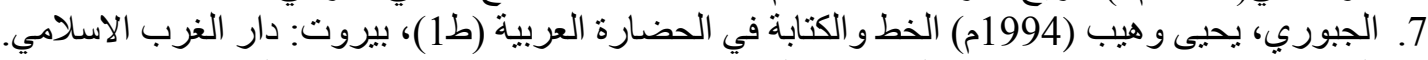
8. 9. الجبوري، سهيلة ياسين(1962م). الخط العربي وتطوره في العصور العباسية في العراق، بغداد: المكتبة الإنية الاهلية

10. الجبوري، سهيلة ياسين(1977م). اصل الخط العربي وتطوره حتى نهاية العصر الاموي، بغداد ؛المكتبة الاهلية 11. حاجي خليفة، مصطفى بن عبد الله( 1943 م). كثف الظنون عن اسامي الكتب و الفنون استانبول :وكالة المعارف 12. سين نصار (2002م). نشأة الكتابة الفنية في الادب العربي( ط1)، القاهرة مكتبة الثقافة الدينية

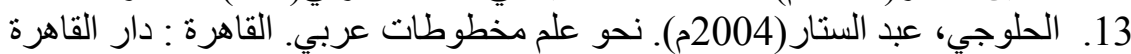

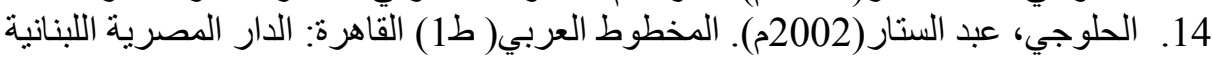

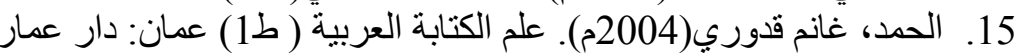

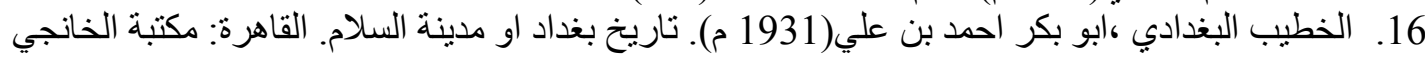

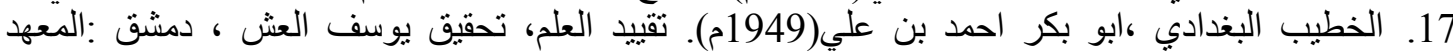
الفرنسي للار اسات العربية 


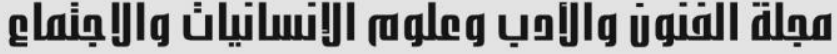

ustlla giant the

Journal of Arts, Literature, Humanities and Social Sciences www.jalhss.com

18. الذهبي، شمس الدين ابو عبد اللة(1333هـ). تذكرة الحفاظ( ط2) الهند: مطبعة مجلس دائرة المعارف النظامية

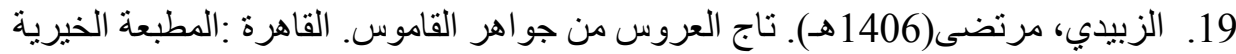
20. السامرائي، قاسم(2001م). علم الاكتناه العربي الاسلامي ( ط1) الرياض: مركز الملك فيصل للبحوث الاسلامية

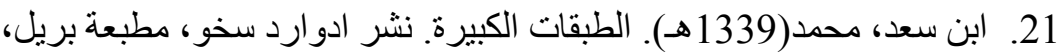

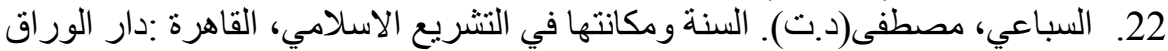

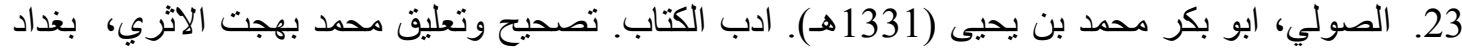
:المكتبة العربية:

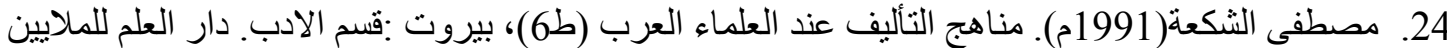

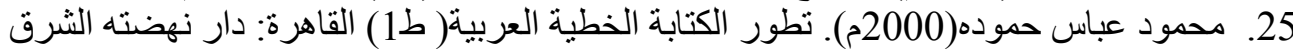

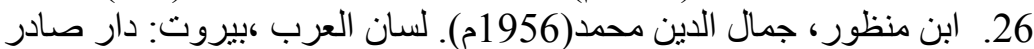

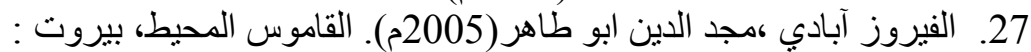

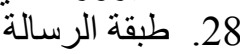

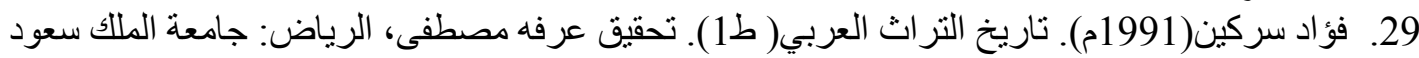

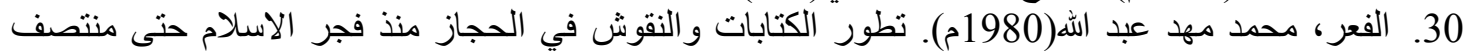

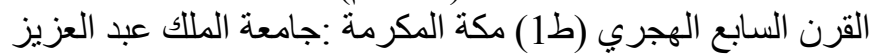

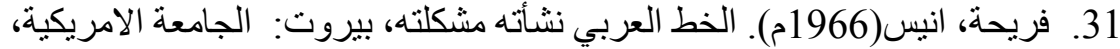

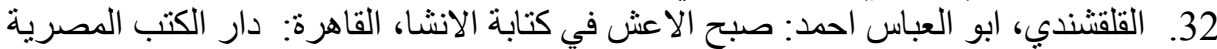

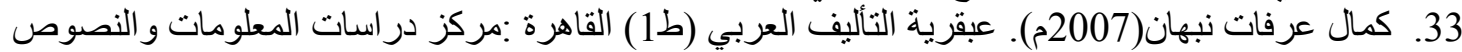

34. الكردي، محمد طاهر (1993م). تاريخ الخط العربي و أدبه( ط1) القاهرة :المطبعة التجارية الحديثة

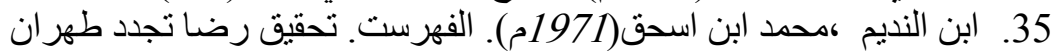

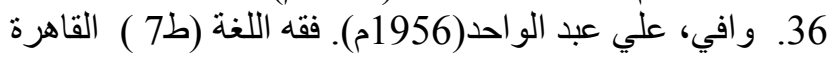

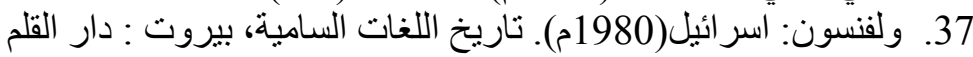




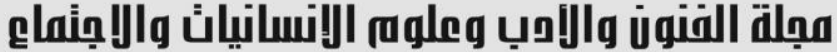 \\ Journal of Arts, Literature, Humanities and Social Sciences www.jalhss.com

\section{References}

1. -Ibrahim Jumaa (1947), The Story of Arabic Writing. Egypt: Dar Al Ma'aref

2. -Baalbaki, Ramzi: The Sublime Arabic Writing (N.D). Beirut: House of Science for the Millions, Beatrice Grindler (2004). The history of Arabic calligraphy and writing from Nabataeans to the beginnings of Islam,

- Translation of Sultan Al-Maani, Jordan: The National Library.

- Al-Thaalabi, Abu Mansour Abd Al-Malik (1954 ): Philology and the Secret of Arabic (2nd Edition), edited by Mustafa Al-Sakka and others, Cairo: Mustafa AlHalabi Library

- Al-Jahez, Abu Othman Amro (1938 ) Al-Hiwan, edited by Abdel Salam Haroun, Cairo: Al-Mustafa Al-Babi Al-Halabi Library

3. -Jawad Ali (1957 ) History of the Arabs before Islam. Baghdad: The Irhaqi Scientific Society Press,

- Al-Jubouri, Yahya Wahib (1994 ) Calligraphy and Writing in Arab Civilization (1st Edition), Beirut: Dar Al-Gharb Al-Islami.

- Al-Jubouri, Yahya Wahib (1988 ): The Book of Islamic Civilization (1st Edition), Beirut: Dar Al-Gharb Al-Islami.

4. -Al-Jubouri, Suhaila Yassin (1962 ). Arabic Calligraphy and Its Development in the Abbasid Era in Iraq, Baghdad: The National Library.

5. -Al-Jubouri, Suhaila Yassin (1977). The origin and development of Arabic calligraphy until the end of the Umayyad era, Baghdad; Al-Ahlia Library

6. -Haji Khalifa, Mustafa bin Abdullah (1943). Detecting suspicions on the names of books and arts, Istanbul: The Knowledge Agency

7. -Hussein Nassar (2002). The emergence of artistic writing in Arabic literature ( $1^{\text {st }}$ ed), Cairo Library of Religious Culture

8. -Al-Halogi, Abdul Sattar (2004). Towards Arabic manuscript science. Cairo: Cairo House

9. -Al-Halouji, Abdul Sattar (2002). Arabic Manuscript ( $1^{\text {st }}$ ed) Cairo: The Egyptian Lebanese House

10. -Al-Hamad, Ghanem Qaddouri (2004). Science of Arabic Writing (1st ed.) Amman: Dar Ammar

11. -Al-Khatib Al-Baghdadi, Abu Bakr Ahmed bin Ali (1931 ). The history of Baghdad or the city of peace. Cairo: Al-Khanji Library

12. -Al-Khatib Al-Baghdadi, Abu Bakr Ahmed bin Ali (1949 ). Restricting Science, Yusef al-Ush's investigation, Damascus: French Institute for Arab Studies.

13. -Al-Dhahabi, Shams al-Din Abu Abdullah (1333 AH). Preservation Ticket (2nd ed.) India: Systematic Knowledge Council Press.

14. -Al-Zubaidi, Mortada (1406 AH). Bride Crown from Dictionary Jewels. Cairo: Charity Press.

15. -Al-Samarrai, Qasim (2001). The science of Islamic Arabic Ictna (1Ed). . Riyadh: King Faisal Center for Islamic Research 


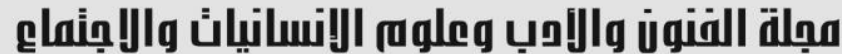 \\ Journal of Arts, Literature, Humanities and Social Sciences www.jalhss.com

16. -Ibn Saad, Muhammad (1339 AH). The large classes. Publishing by Edward Schw, Braille Press.

17. -Al-Sebaei, Mustafa (N.D). The Sunnah and its place in Islamic legislation, Cairo: Dar al-Warraq.

18. -Al-Souli, Abu Bakr Muhammad Bin Yahya (1331 A.H.). Literature of the book. Correction and Commentary by Muhammad Bahjat Archaeological, Baghdad: The Arab Library.

19. -Mustafa Shakaa (1991). Authorship curricula for Arab scholars (6 th ed. ), Beirut: Literature Department. House of science for millions.

20. -Mahmoud Abbas Hamouda (2000 ). The evolution of Arabic calligraphy (1Ed) Cairo: The House of its East Renaissance

21. -Ibn Manzoor, Jamal al-Din Muhammad (1956 ). Lisan Al Arab, Beirut: Dar Sader

22. -Al-Fayrouzabadi, Majd Al-Din Abu Taher (2005). The Ocean Dictionary, Beirut:Tabakat al-Resalaa

23. -Fouad Sarkin (1991). History of Arab heritage ( 1st Ed). An investigation known by Mustafa, Riyadh: King Saud University

24. -Al-Fa'r, Muhammad Mahd Abdullah (1980). The development of writings and inscriptions in the Hijaz from the dawn of Islam until the middle of the seventh century AH (1st ed.) Makkah Al-Mukarramah: King Abdulaziz University

25. Fariha, Anis (1966 ). Arabic Calligraphy Has Its Problem, Beirut: American University.

- Al-Qalqashandi, Abu Al-Abbas Ahmad: Subuh Al-Aash in Writing Al-Insha, Cairo: Dar Al-Kutub Al-Masrya.

26. -Kamal Arafat Nabhan (2007 ). The Genius of Arabic Authorship (1st ed.) Cairo: Center for Studies of Arabic Information and Texts

27. -Al-Kurdi, Muhammad Taher (1993). History and Literature of Arabic Calligraphy (1st ed.) Cairo: Modern Commercial Printing Press.

28. -Ibn al-Nadim, Muhammad Ibn Ishaq (1971 ). Index. Achieving the satisfaction of Tehran renewed.

29. -Wafi, Ali Abdul Wahid (1956). Philology ( $7^{\text {th }}$ ed) Cairo

30. -Wolfensohn: Israel (1980). History of Semitic Languages, Beirut: Dar AlQalam. 